\title{
Should or should not forensic psychiatrists think about free will?
}

\author{
Gerben Meynen
}

Published online: 15 October 2008

(C) The Author(s) 2008. This article is published with open access at Springerlink.com

\begin{abstract}
The forensic psychiatrist's task is often considered to be tightly connected to the concept of free will. Yet, there is also a lack of clarity about the role of the concept of free will in forensic psychiatry. Recently, Morse has argued that forensic psychiatrists should not mention free will in their reports or testimonies, and, moreover, that they should not even think about free will. Starting from a discussion on Morse's claims, I will develop my own view on how forensic psychiatrists are confronted with the issue of free will and how they should deal with this concept and the confusion surrounding it. I conclude that psychiatrists should at least feel free to think about free will and that the conceptual challenges connected to the issues of free will and accountability could rather encourage than deter forensic psychiatrists to think about them.
\end{abstract}

Keywords Psychiatry - Forensic psychiatry - Free will · Mental disorder · Freedom · Responsibility · Philosophy · Law

\section{Introduction}

The forensic psychiatrist's task is often considered to be tightly connected to the concept of free will. ${ }^{1}$ Yet, there is also a lack of clarity about the role of the concept of free will in forensic psychiatry. Important issues are whether free will is indeed a criterion for responsibility in forensic matters, and, if free will is indeed a criterion, to which

\section{G. Meynen ( $\square)$}

Department of Philosophy, EMGO Institute VU Medical Center,

VU University Amsterdam, De Boelelaan 1105, $1081 \mathrm{HV}$

Amsterdam, The Netherlands

e-mail: g.meynen@ph.vu.nl extent forensic practitioners should be concerned with philosophical considerations about free will, like the problem of the compatibility of free will and determinism. ${ }^{2}$

Recently, Morse (2007) has made a gripping argument which led him to conclude that it would be wise for forensic psychiatrists not to mention free will in their forensic reports or testimonies, and, moreover, that they would not even think about free will. ${ }^{3}$ For free will would not be a necessary concept in forensic matters, and on this point Morse is supported by Felthous (2008). ${ }^{4}$ Using 'free will' in forensic reports or deliberations would only lead to confusion, according to Morse. Given the drastic measure Morse arrives at-that forensic psychiatrists should completely avoid thinking about free will-it is important to carefully examine his argument within the broader context of forensic and philosophical debates on free will and responsibility. Starting from a discussion on Morse's line of thought, I will develop my own view on how psychiatrists should and should not deal with the lack of clarity surrounding the issue of free will in forensic psychiatry.

I will distinguish two basic claims in Morse's paper relevant to the general discussion on free will and forensic psychiatry. The first claim is about the "practical' ${ }^{5}$ issue

\footnotetext{
1 See, e.g., Luthe and Rösler (2004), Morse (2007), or Van Marle (2000) in footnote 15 of this paper.

${ }^{2}$ See, e.g., Felthous (2008), Morse (2007) and Wilson and Adshead (2004).

${ }^{3}$ Morse's paper is about forensic psychiatrists and psychologists. In this paper I will restrict my argument to (forensic) psychiatrists.

${ }^{4}$ See also Buchanan (2008, p. 25): "Morse's reassuring conclusion, in the paper that Felthous (2008) cites, is that while there may be questions about free will, it need not be a particular problem for forensic psychiatrists. The criminal courts are often said to assume that defendants have free will."

5 The practical issue is what I will later refer to as the ethical issue.
} 
that forensic assessments do not have to do with free will at all. If this claim is correct, then forensic practitioners do not have to worry about free will. ${ }^{6}$ The second claim concerns the 'metaphysical' issue that moral responsibility and determinism are compatible. Within the framework of Morse's paper this would mean that neither philosophers nor anyone else-among whom psychiatrists-would have to worry about the problem of free will. So, if both claims can be proven to be right, then everyone, including the forensic psychiatrist, can put his or her mind to rest, at least as far as the problem of free will is concerned.

Both claims will be addressed in this paper. The issue at stake is whether forensic psychiatrists should or should not think about free will. Section "The practical argument: on what is required for responsibility" is concerned with the 'practical' issue of forensic psychiatric assessment and free will, and in Sect. "The metaphysical argument: on the compatibility of free will and determinism" the "metaphysical' topic of the compatibility of free will or moral responsibility and determinism is discussed. I argue that it is important to clearly distinguish between the ethical issue about what is needed for moral responsibility ${ }^{7}$ and the metaphysical issue of the compatibility of freedom and determinism. While the former is of direct relevance to the forensic psychiatrist's task, the latter is not. In Sect. "On what (forensic) psychiatrists should and should not do and think about", I will, based on this distinction, present my position on what forensic psychiatrists should and should not do or think about given current discussions-and confusion — on free will and moral responsibility.

Although free will is central in this paper, I will not define 'free will'. Many people may have different intuitions on what it would take to have free will. According to Walter (2001), three main aspects or components of free will can be distinguished in the current philosophical debate. The first component is, that to be free, one must be able to do otherwise. Second, to be free means to act or choose for an understandable reason. And, third, freedom requires that one is the originator of one's actions. The current philosophical freedom debate is for a large part concerned with the question to which extent these aspects really are essential to the concept of free will, and if so, in what way (Watson 2003; Frankfurt 2003; Kane 1998,

\footnotetext{
${ }^{6}$ See also Felthous (2008, p. 21)

7 According to the online Stanford Encyclopedia of Philosophy (entry Moral Responsibility), "A comprehensive theory of moral responsibility would," among other things, "elucidate the conditions under which the concept of moral responsibility is properly applied, i.e., those conditions under which a moral agent is responsible for a particular something (e.g., a moral agent can be responsible for an action she has performed only if she performed it freely, where acting freely entails the ability to have done otherwise at the time of action)".
}

2002). In this paper I will not take a position on how to understand free will, and I will not try to solve the conceptual problems surrounding it. My point of departure is that there is a widespread intuition in the literature-not only among forensic psychiatrists but also among philosophers - that if anything is important to moral responsibility, it is free will. At the same time, free will is understood in different ways (see also Sect. "The practical argument: on what is required for responsibility"), and that its exact relation with moral responsibility is not clear. The paper addresses the practical issue of how psychiatrists could operate in their forensic work given the forensic task and given the current philosophical debate on free will and the conceptual complexities surrounding it.

\section{The practical argument: on what is required for responsibility}

According to Morse (2007), there are several ways in which forensic practitioners can be confused about free will. He even distinguishes_- "tongue-in-cheek"—a "Free Will Confusion Syndrome". The Free Will Confusion Syndrome has six features, and manifesting any one of the signs or symptoms is sufficient to make the diagnosis. In addition, the number of criteria manifested by a person indicates the disorder's severity (Morse 2007, p. 219). I will not discuss each of the six features he describes, but I will mention the three features that are central to his view. These are, first, believing that psychiatry or psychology have any data to contribute to whether a particular person has free will. Second, believing that free will or its lack is a legal criterion for responsibility and excuse. Third, using "free will" as a premise or conclusion in a forensic argument. For example, "the defendant lacked free will and was therefore legally insane" or "the defendant lacked free will." ${ }^{8}$ And according to Morse (2007, p. 219), "many" forensic practitioners suffer from the syndrome, that is "most generally marked by the erroneous belief that free will is a specific or foundational criterion for responsibility in morality and law."

As I understand Morse, examples of this confusion would be Reich (2000, p. 206), who says that "the law recognizes that insanity compromises free will, and classifies someone without free will as legally not responsible for his or her actions (...)" and Luthe and Rösler (2004, p. 297) who state that in case the court consults psychiatric experts, these experts "whether they want to or not, will

\footnotetext{
8 The three other features of the 'Free Will Confusion Syndrome' are: Believing that science can solve the free will problem. Believing or saying that causation excuses or mitigates responsibility. Believing or saying that causation is the equivalent of compulsion (Morse 2007, p. 219).
} 
have to concern themselves with the question of whether human actions can be freely chosen or whether the acting person could not avoid acting as he did." ${ }^{9}$ Yet, according to Morse, free will has nothing to do with the practice of forensic assessments and forensic psychiatrists, therefore, have nothing to do with the conceptual problems related to free will: "The only practical free will problem is the confusion among forensic practitioners and others who think that free will is a problem or who speak and write as if it is." 10

Instead of free will, according to Morse, there are other phenomena or criteria that should be addressed when assessing whether a particular person is responsible for a certain legally relevant act. In order to show what criterion (instead of free will) is really important from a legal point of view, Morse addresses 'the legal view of a person'. The legal view of a person is, he argues, that a person is a rational being capable of letting himself be guided by rules:

The law's view of the person is a creature capable of practical reason, an agent who forms and acts on intentions that are the product of the person's desires and beliefs. The law does not treat persons generally as non-intentional creatures or mechanical forces of nature. It could not be otherwise. Laws could not guide people ex ante and ex post unless people were the types of creature who could use laws as premises in their practical reasoning (...). The law's concept of responsibility follows logically from the nature of law itself and its concept of the person (...). Unless human beings were rational creatures who could understand the good reasons for action, including the relevant facts and rules, and could conform to legal requirements through intentional action, the law would be powerless to affect human action. Legally responsible agents are therefore people who have the general capacity to grasp and be guided by good reason in particular legal contexts. ${ }^{11}$

In Morse's view, from this line of thought it follows that rationality is the phenomenon that grasps the legal view of a person. ${ }^{12}$ Although Morse does not refer to any specific

\footnotetext{
9 See also by Luthe and Rösler (2004, p. 296), "Modern criminal law has (...) not fundamentally escaped the question of freedom (...)."

${ }^{10}$ Morse (2007, p. 204).

11 Morse (2007, p. 205, my emphasis on 'rational').

12 Morse (1999) goes in more detail on his view on rationality in forensic matters. I will, however, focus on Morse's 2007 argument about how psychiatrists should deal with 'free will'. Felthous (2008, p. 21) seems to side with Morse in an important respect. He considers Morse to have made "a strong argument that the concept of a metaphysically free will is unnecessary for sustaining the purposes of the legal system in the United States." Meanwhile, according to Wilson and Adshead (2004, p. 301), "[w]e have a powerful sense of our own ability to freely choose our behavior, and this is the common-
}

legal study or forensic document to substantiate this view, at the end of the quote Morse refers to a study by R. Jay Wallace (1994, p. 1). Wallace, a philosopher, developed an argument concerning moral responsibility and he writes: "Being a responsible moral agent, I believe, is not really a matter of having freedom of the will. Rather it primarily involves a form of normative competence: the ability to grasp and apply moral reasons, and to govern one's behavior by the light of such reasons." While Morse refers to Wallace to support his interpretation of legal responsibility, it is in my view questionable whether the term 'rationality' completely captures what Wallace describes here. For his point does not only seem to be about understanding and applying reasons, but also about being able to guide or govern one's behavior. In fact, Wallace's final conclusion is not that what is needed for moral responsibility is rationality, but that "general powers of reflective self-control" are required (see, e.g., 1994, p. 194). So, what is important in Wallace's account is also a notion of control (of one's behavior or oneself). And in my view such a notion of control is also implicitly present in Morse's 'legal view of a person' as quoted above, since a person "could conform to legal requirements through intentional action".

Why should not we overlook this element of control? In current philosophical discussions on free will (and moral responsibility) control is a central issue. The common view is that freedom requires control. The Stanford Encyclopedia of Philosophy (Entry Free will) reads: "Our survey of several themes in philosophical accounts of free will suggests that a-perhaps the-root issue is that of control." 13 Kane (1999, p. 219) provides a good illustration of this view: "We are often asked to consider, for example, that whatever is undetermined or happens by chance is not under the control of anything, and so is not under the control of the agent. But an action that is not under the control of the agent could not be a free and responsible action." 14 In addition, according to some philosophers, control is not only a necessary but also a sufficient

Footnote 12 continued

sense view of the law." Cf. Eastman (1992, p. 161): "Considering only criminal law, the heart of the definition of most crimes (actus reus plus mens rea) incorporates the requirement of (varying degrees of) intention, that is, it invents intentional man. It implies a model of human behaviour which is clearly exclusively cognitive in nature, unitary (in relation to each defined crime), and based on a presumption of free will rather than (scientific) determinism."

${ }^{13}$ See about control in relation to free will and moral responsibility (and the possibility of a deterministic world), also Fischer 1994 and, together with Ravizza 1998. Mele (2004, p. 78) also discusses, based on Elliot's (1996) study about The Rules of Insanity. Moral Responsibility and The Mentally Ill Offender, control in relation to mental disorders. See also Felthous (2008, pp. 21-22) on control.

14 This quote already shows something that will be explicitly discussed further in the paper: that in the current philosophical debate matters of freedom and responsibility are intertwined. 
condition for freedom. As Benson (1987, p. 477) puts it: "It is true that most writers have assumed as a matter of course that freedom consists in nothing more than control." Benson (1987, p. 485) even observes a "dogmatic conviction that freedom simply cannot consist in anything more than control or ability to do otherwise." So, while Morse does not mention freedom or free will in 'the legal view of a person' this does not mean that the notion of 'free will' is eliminated in his account.

Morse seems to intend to show that one can deliver an account on the legal view of a person without mentioning 'free will', and Felthous (2008) agrees with Morse that the United States law does not mention free will. ${ }^{15}$ Yet, although it is good and refreshing to look at the exact phrasings in the legal documents, we should realize that the (philosophical) question at stake could still be somewhat different. It could be about whether the concept of free will is implicitly present, or whether it can even be considered guiding the law in some relevant or even vital way. To drive the point home, even if we consider a certain concept—let us say rationality or control—vital to grasp the legal notion of a responsible person, then, still, one would have to show how exactly it relates to the concept of free will. Not mentioning free will does not at all guarantee that (a certain notion of) free will is not implied.

As a further illustration, let us return to Wallace. $\mathrm{He}$ indeed states that free will is not needed for moral responsibility. Yet, what he in fact means to say is, as he puts it in Précis of Responsibility and the Moral Sentiments (2002, p. 680): "[T] he general powers for moral reasoning and response that make us accountable, on my theory, do not involve or presuppose the kinds of alternative possibilities for action traditionally associated with freedom of will." This means that Wallace's point is in the end not that free will as such is not necessary for moral behavior, but that alternative possibilities (one of the aspects of free will

\footnotetext{
15 In general, there are different juridical systems in different countries, and the exact task or description of the task of a forensic psychiatrist may differ. See, e.g., on English law and Anglo-American jurisdictions Wilson and Adshead (2004, pp. 298, 303), Green et al. (1991), and see Van Marle (2000), on forensic assessments in the Netherlands: "Undiminished responsibility means that the person concerned had complete access to his or her free will at the time of the crime with which he or she is charged and could therefore have chosen not to do it. Irresponsibility means that the person concerned had no free will at all with which to choose at the time of the crime with which he or she is charged. Important here is determining the moment when aspects of the disorder become manifest in the situation ("the scene of the crime") that will eventually lead to the perpetration. The earlier they play a role, the more inevitable will be the (disastrous) sequence of events, and the stronger will be the eventual limitation of free will." Yet, in my view, the issue at stakethe issue of forensic psychiatry and matters of free will and moral responsibility - transcends national legal borders and specific national phrasings of the task of forensic psychiatrists.
}

that is being debated in the philosophical discussions, see Walter 2001) are unnecessary. And it is important to note that dropping the feature of alternative possibilities does not eliminate 'free will' from the discussion. Also Frankfurt (2003, p. 344), who provided an influential ${ }^{16}$ argument to show that moral responsibility does not require alternative possibilities, still uses the term 'free will', e.g., as he says that blaming a person may be reasonable "when the person has performed the action in question (...) entirely for reasons of his own and thus of his own free will."

So, while Morse emphasizes that relevant legal documents do not mention free will as a requirement for accountability, this does not provide us with a conclusive argument that free will just does not have to do with the practice of assessing moral or legal responsibility. To exemplify this point I showed that from the 'legal view of a person', as presented by Morse, it does not follow that what is required is only 'rationality'. ${ }^{17}$ Control might be involved as well, and this concept is considered to be closely linked to-or, apparently, sometimes even identical with-the concept of free will.

In fact, what we have been discussing here, is what I consider the 'ethical' problem concerning free will, namely the question: What is required for responsibility? Morse answers this question by interpreting 'the legal view of a person' as being essentially about rationality. ${ }^{18} \mathrm{He}$ relies strongly on the exact phrasing in legal documents, and I have tried to show that even if one would follow his view of a legal view of a person, it is not clear that this means that the concept of free will no longer applies. The basic idea I wanted to convey is that not mentioning free will does not mean that the concept of free will has been cut out or has become irrelevant.

Felthous's (2008) paper on forensic psychiatry and free will is in important respects supportive of Morse's view (see also Buchanan 2008). Felthous proposes to leave out the 'free' part of free will. According to Felthous (2008, p. $21)$, "[t]he law defines mental responsibility and competence by the presence or absence of certain capacities or functional abilities or by the specific actual, active functions such as specific intent and deliberation (...). "Free" will is not involved." While proposing to drop the "free'

\footnotetext{
16 See Ginet (2003, p. 76).

${ }^{17}$ Surely, the law does not seem to be written from the perspective that a person is in principle irrational, and it is safe to say that 'rationality' is important to legal responsibility, but what I have tried to show is that from this it does not follow that rationality is sufficient for moral or legal responsibility. For it is not about which concepts are relevant to responsibility, it is about the question whether we are in a position to consider rationality the preeminent requirement for moral responsibility -independent of the notion of free will.

18 Importantly, as Felthous (2008, p. 23) points out: "However, rationality, too, is subject to diverse definitions." Yet, I will not further discuss the issue of rationality in forensic assessment.
} 
part of free will, he argues that the will deserves (more) attention in forensic psychiatry. According to Felthous (2008, p. 23), "[t]he will is simply the intentional faculty: Through motivation and decision the will settles upon and then implements an action." This could be true, but for moral responsibility it might just not be enough that something was 'willed', or that a motivated decision was made. ${ }^{19}$

Although, as indicated, I will not try to define free will, it could be helpful to pay some attention to Felthous's proposal. When he says that " $[\mathrm{t}]$ he will is simply the intentional faculty: Through motivation and decision the will settles upon and then implements an action," one should ask oneself whether this provides sufficient information to distinguish, with respect to accountability, e.g., a legally relevant act performed due to a paranoid delusion from a legally relevant act performed without any mental disorder. Both actions may be motivated, intentional, and both may involve a decision. In order to be able to distinguish between these two cases, therefore, a forensic psychiatrist might want to qualify the motivational and decisional process, and try to examine, e.g., how the intention, motivation, and decision 'came about'. To put it cautiously, some people might start to use the word 'free' here, exactly at the point where the forensic psychiatrist has to make his or her assessment. I am not trying to say that Felthous' s proposal should not be pursued, but that it is important to see whether and how our intuitions on moral responsibility with respect to the forensic task can be fully grasped and articulated when only using the concept of 'will'.

To conclude this section, although the concept of free will and its relation to moral responsibility may be complicated, I do not think that it is justified to infer, based on the arguments presented, that forensic practice as such just does not have to do with free will. In order to get a clearer view on Morse's line of thought that leads him to the farreaching measure that forensic psychiatrists should avoid thinking about free will, and to further develop my own view on the issue of free will and forensic psychiatry, I will now turn to Morse's 'metaphysical' argument.

\section{The metaphysical argument: on the compatibility of free will and determinism}

There is an additional problem related to the concept of free will: the notorious question about the compatibility of free will and determinism. Some people are also worried about this problem within the context of the forensic

\footnotetext{
${ }^{19}$ On the difference between 'will' and 'free will', also see Sebanz and Prinz (2006, pp. 3-5).
}

psychiatrist's task. ${ }^{20}$ They reason, briefly, that if we live in a deterministic world, and if free will is incompatibile with determinism, free will must be an illusion. Then, if the forensic psychiatrists' task is about free will, this task must be illusory in itself.

Morse also pays attention to this topic. It might even be a little surprising that he develops an argument on this what I call the 'metaphysical' issue of the compatibility of free will and determinism. For if forensic psychiatry has nothing to do with the concept of free will, as he claims, why bother about the compatibility of free will and determinism, or the metaphysical positions on free will, moral responsibility and determinism? Yet Morse (2007, p. 212) addresses this issue because people, "including judges, practicing lawyers and a few law professors, talk as if free will were important in criminal law, but this is clearly wrong as a matter of positive law. They sometimes mean (...) that free will is a necessary foundational justification for responsibility, even if it is not a criterion in any legal doctrine." He argues that such a concern about conceptual problems surrounding free will is needless, for there is an "entirely plausible and practical" resolution of the metaphysical problem. But can we, indeed, consider this problem resolved?

The three main philosophical positions on free will and determinism are: libertarianism, hard determinism and compatibilism. I will introduce these three positions in this section, and discuss Morse's view on them. 'Libertarians' and 'hard determinists' may disagree on almost everything, but they agree that free will and determinism are incompatible. Libertarians deem free will true, and, therefore, determinism false. According to Morse (2007, p. 212), "Free will is usually taken to mean, explicitly by philosophers and implicitly by others, that the agent has the ability to cause his or her own behavior uncaused by anything else. In a phrase, the buck stops entirely with the agent." In order to introduce the libertarian position, Morse emphasizes here what can be considered the third element of Walter's (2001) tripartite view on free will: being the source of one's behavior (see also Kane 1998). And he adds that "[o]nly a small number of philosophers adhere to this view, which has been termed a "panicky" metaphysics because it is so implausible." Morse refers in a footnote to the philosopher Bok (1998), who indeed considers the libertarian position 'implausible'. Still, the idea that libertarianism is 'implausible', as Morse puts it, is not generally agreed on in the metaphysical discussion; it is simply a position in the debate. And the 'implausibility' of libertarianism, therefore, cannot be considered a sort of

\footnotetext{
${ }^{20}$ See for example Wilson and Adshead (2004, p. 301) on "the confusing issues of free will and determinism" with respect to forensic assessments.
} 
'fact' (see, e.g., Kane 1998). Bok (and Morse) may, in principle, turn out to be right, but it is not yet 'decided'. With respect to the connection between the libertarian view and the law, Morse says that many people believe that libertarianism is "a foundational assumption for law". 21 He, however, will later argue that a libertarian notion of free will is not necessary to save moral and legal responsibility.

Hard determinists hold that determinism is true and that, therefore, free will is false. ${ }^{22}$ The major problem for hard determinists is to explain our moral intuitions and to explain how we should deal with them after we have realized that free will is 'illusory'. Morse understands the hard determinist position primarily as a position about the incompatibility of determinism and moral responsibility. If the hard determinists are right, then "forensic psychiatrists, forensic psychologists, and everyone else have a massive and genuine free will problem because all mental health laws depend on the non-responsibility assumption, which in turn assumes that most people are responsible, that responsibility is the default condition" (Morse 2007, p. 214). So, while Morse has tried to show in the previous section that legal responsibility does not have to do with the issue of free will, he says here that there would be a 'massive and genuine free will problem' for legal practices in case hard determinism is true. ${ }^{23}$ If Morse is right in this view on hard determinism, then, as long as the truth of hard determinism is on the cards, there seems to be something to worry about for forensic practitioners.

Compatibilism is, in principle, just the view that free will and determinism can get along perfectly well. Yet, compatibilists usually have some slightly other view of free will than the ('incompatible') libertarian view; they generally do not demand from free will what libertarians demand from it. They are satisfied with some softer conception of free will, but they consider this conception still worthy to be called 'free will'. Morse turns out to be a kind of compatibilist and he argues (2007, p. 216) that "even if determinism is true, forensic psychiatry and psychology have no practical free will problem because the doctrines of responsibility are entirely consistent with the truth of determinism or because responsibility is impossible tout court." A libertarian conception of free will-being the source of one's actions "is not necessary to underwrite our

\footnotetext{
21 Stanford Encyclopedia of Philosophy (Entry Moral responsibility): "For example, some have argued that while a compatibilist sense of freedom is necessary for attributability, genuine accountability would require that agents be capable of exercising libertarian freedom."

22 Morse (2007) refers to hard determinists as "incompatibilists'.

${ }^{23}$ See also Kawohl and Habermeyer (2007, p. 309): "The free will debate widely exceeds the neuroscientific and philosophical fields due to profound implications for legislation, case law and psychiatric expert opinion."
}

positive conceptions of responsibility." And Morse (2007, p. 216) concludes that "[b]ecause compatibilism is consistent with our responsibility practices and their centrality and because there is no convincing theoretical reason to reject it, all participants in the legal system, including forensic psychiatrists and psychologists, have good reason to embrace compatibilism. Forensic practitioners can comfortably continue to play a crucial role in helping legal decision makers assess responsibility in all civil and criminal law contexts without being distracted by the irrelevant issue of free will." As it seems, the fact that forensic practitioners can comfortably continue to play a crucial role in helping judges by assessing responsibility relies in the end on the fact that determinism is compatible with moral responsibility.

We have to note that Morse considers compatibilism to be a thesis about the compatibility of determinism and moral responsibility. Yet, usually compatibilism is first of all considered to be a thesis about determinism and free will. $^{24}$ Importantly, from embracing compatibilism it does not at all follow that there would no longer be an issue of free will related to moral responsibility. In fact, compatibilists can very well consider free will (in some 'softer' form) necessary for moral responsibility. Compatibilists might even want to argue for compatibility exactly because they do consider free will necessary for moral responsibility. In general, one of the important reasons - if not the reason-why free will is so central in philosophy is exactly the supposed importance to responsibility, as Van Inwagen (1986, p. 153) puts it: "[W]e care about free will because we care about moral responsibility, and we are persuaded that we cannot make ascriptions of moral responsibility to agents who lack free will." 25 So, from this perspective, the metaphysical worries about the compatibility of free will and determinism are fuelled by the ethical intuition that free will is required for moral responsibility.

Importantly, compatibility problems do not only arise as long as we use the concept of free will. For the compatibility question can, as we saw, also be expressed in terms of the compatibility between determinism and moral responsibility or legal accountability, without referring to (a specific notion of) free will. So, ignoring or avoiding the concept of free will, will as such not free us from a metaphysical compatibility problem.

\footnotetext{
$\overline{24}$ According to the Stanford Encyclopedia of Philosophy, "Compatibilism is the thesis that free will is compatible with determinism. Because free will is taken to be a necessary condition of moral responsibility, compatibilism is sometimes expressed in terms of a compatibility between moral responsibility and determinism." (http:// plato.stanford.edu/entries/compatibilism).

25 This does surely not mean that (the nature of) the relationship between free will and moral responsibility is clear. See also, e.g., Nagel (2003) and P.F. Strawson (2003, pp. 72-73).
} 
Now, in my opinion it is helpful to forensic psychiatry to make a distinction between these two topics: on the one hand the ethical issue concerning the question what is needed for responsibility and on the other hand the metaphysical worries about the compatibility of free will and determinism. These issues are separable, and although forensic psychiatrists are not asked to make judgments about the compatibility question, they are asked to make an assessment with respect to what is needed for responsibility.

Morse seems to be convinced that even if determinism is true, moral responsibility can be saved. Meanwhile he says that, indeed, there is no definite solution to the compatibility problem: "There are no decisive, analytically incontrovertible arguments to resolve the metaphysical question of the relation between determinism, libertarian free will and responsibility" (2007, p. 213). Morse's dealing with the metaphysical problem is interesting and provocative, yet it is not conclusive. This means that the metaphysical free will problem can be considered intact. For instance, with respect to this problem the philosopher Searle (2007, p. 11) remarks:

The problem of free will is unusual among contemporary philosophical issues in that we are nowhere remotely near having a solution. I can give you a pretty good account of consciousness, intentionality, speech acts and of the ontology of society, but I do not know how to solve the problem of free will.

To summarize, Morse argued that forensic concerns about the problem of free will are needless, for there would be an entirely plausible and practical resolution of the metaphysical free will problem. He then tried to show that the compatibility question can be considered resolved. Yet, in my opinion, given the fact that the metaphysical compatibility question cannot be considered resolved, Morse would - within the framework of his project-leave the door open to the compatibility question in forensic psychiatry.

As a matter of fact, I think that there is no need to try to resolve the compatibility question in order to free forensic psychiatrists from this metaphysical enigma. For the important step to be taken is to disentangle the ethical and metaphysical issue and to say that, yes, forensic psychiatrists have to do with the ethical debate on what is required for moral responsibility-and in this debate free will is a central issue - and that, no, forensic practitioners do not have to address the compatibility question. There are many (or rather endless) philosophical issues, and only some of them will be directly relevant to forensic practice. Yet, the question "What is needed in order to be held responsible?" is relevant to forensic psychiatry, I argue. And it is my claim that if the discussions on this matter involve the concept free will, which is the case, then psychiatrists should not keep aloof from this concept just to avoid to get into (compatibility) trouble. ${ }^{26}$ The practical consequence of taking the distinction between the ethical and metaphysical issue seriously and acknowledging that free will plays a role in the discussions on moral responsibility, is that forensic practitioners do not have to stop thinking about free will.

Analogous to Morse, while discussing his analysis, in this section I have tried to provide my view on the bearings of the philosophical debate for the practice of forensic psychiatry. I value the metaphysical debate differently: while Morse emphasizes the implausibility of libertarianism, the plausibility of compatibilism, and the enormous consequences of hard determinism to legal practices, I emphasize the inconclusiveness of the metaphysical debate on the compatibility question, and the fact that this metaphysical topic can and should be distinguished from the practically relevant ethical question about what is needed for moral responsibility. In my view, forensic psychiatrists cannot distance themselves from what I call the ethical question-because forensic assessment is exactly about what is needed for responsibility - while they can distance themselves from the compatibility question.

\section{On what (forensic) psychiatrists should and should not do and think about}

Let us now look more closely at the question what forensic psychiatrist should and should not think about. Certainly, there is no need for individual psychiatrists trying to make philosophical arguments on what is required for moral responsibility while reporting on a particular forensic case. But I would like to add that there is also no need for individual psychiatrists unraveling the sociological or neurobiological factors relevant to delinquent behavior while reporting on a particular forensic case. Yet, from this it does not follow that psychiatrists as professionals should not study such factors in scientific research. Clearly, also a doctor or psychiatrist should not wait until he has solved the conceptual problems concerning the concept of 'disease' or 'mental disorder' before treating a patient, but this does not mean that doctors should not think about the concept of disease, or that the medical profession should not pay careful attention to the way the concept of disease or mental disorder can be understood. In fact, the conceptual issues might be best addressed in scientific research

\footnotetext{
${ }^{26}$ Meanwhile, the German psychiatrist Emil Kraepelin (1856-1926, well-known for his view on schizophrenia, 'dementia praecox' in his words) seems, at least in a way, to support Morse and Felthous: "Kraepelin did not want to engage himself in the philosophical debate about determinism. Instead, his aim was to reject all "metaphysical" implications in (forensic) psychiatry, like the idea of an apriorical free will and to emphasize the naturalistic quality of all social and psychological phenomena" (Hoff 1998, p. 351).
} 
projects, in which, preferably, philosophers and forensic practitioners (and lawyers) could cooperate.

So, I would propose not only to distinguish between the ethical and metaphysical issue, but also to distinguish between the individual psychiatrist making an assessment, and the professional community of forensic practitioners having to deal with certain conceptual challenges. The professional community has, in my view, a broader and deeper responsibility for conceptual issues within its domain than the individual practitioner, and interdisciplinary research might be a good way to address them. Individual forensic professionals, in turn, might be helped by such research in obtaining better conceptual tools that improve the quality of their judgment.

In any case, it would be strange that while the concepts of free will and moral responsibility are so intimately related, psychiatrists have to think about one of these while avoiding the other completely. In addition, concepts are related to other concepts and forensic psychiatrists should be free to go in their conceptual framework. How psychiatrists should phrase their forensic reports, is yet another issue. And, surely, forensic assessment might be helped by or even require the 'operationalization' of certain complicated concepts, for instance moral responsibility. ${ }^{27}$ Factors like memory, consciousness and rationality ${ }^{28}$ could be important to forensic assessments and testimonies. But their importance would not mean that free will is no longer relevant; in fact, these factors might even be considered operationalizations of what it is like to be a 'free and responsible agent'.

How could forensic practitioners in a particular case benefit from thinking about free will? Well, maybe psychiatrists who are to assess whether a mental disorder has in a legally relevant way to do with some person's action, could use some counterpoint in their deliberations. They might be helped by having at least some idea about what it is like if no disorder is involved in a person's behavior. Some, or many, might call this a state of freedom or free will. It might be helpful to a psychiatrist, weighing all the information, to consider whether the state in which the person was, resembles this 'free' state, or whether there is some essential divergence from this 'free' state. The state of freedom is in this case a counterpoint in the deliberation. Free will would be some 'guiding' idea. This might not be wrong at all, even not in a particular forensic case. Or, put more cautiously, I do not think that Morse has shown it to be wrong. Then, what would be the practical consequence if his proposal would be put to practice? Forensic

\footnotetext{
27 See also Wilson and Adshead (2004, p. 296): "What "criminal responsibility" might mean and how it might be measured has caused a good deal of discussion among psychiatrists, philosophers, and lawyers. There is general agreement that the term is problematic. There is not general agreement on the source of the problem."

${ }^{28}$ Morse (2007), see also Felthous (2008).
}

psychiatrists would alienate themselves from the general debate on moral responsibility and from a key intuitionwhich, surely, does not necessarily mean it is right—on moral responsibility. Trying to avoid this discussion and this key intuition could hamper their assessment, which is exactly about assessing responsibility. There may be compelling arguments to avoid major debates and key intuitions, but I do not think they are provided in this case.

There is a more general issue, still. Indeed, conceptual confusion about free will and its relation to moral responsibility does exist. Yet, we should consider that if psychiatrists would have to stop thinking at points at which their profession touches upon conceptually problematic issues, psychiatrists could be ending up avoiding many concepts. For the domain of psychiatry seems for a considerable part at least potentially conceptually confusing. ${ }^{29}$ For instance, the very concept of 'mental disorder' is in relevant respects complicated (see, e.g., Sadler 2005; Bolton 2008). I think that psychiatrists should, given the conceptual complexity of their profession, not be encouraged to stop thinking about such issues, but rather, as a profession, be encouraged to deal with them. It is important, however, to see exactly which problems are relevant to the practical task.

While I argue that the compatibility question is not (directly) relevant to forensic work, my argument is not meant to bring forward that 'metaphysical' issues per se are detached from the practice of psychiatry. Philosophy should not be primarily considered as 'detached' from forensic issues, ${ }^{30}$ but, in part, as the practice of dealing with the conceptual problems psychiatrists face, e.g., the problem of free will and accountability. And, perhaps not surprisingly, philosophers refer to psychiatry in their papers on moral responsibility and free will. ${ }^{31}$ Apparently, they consider

\footnotetext{
${ }^{29}$ Cf. Sadler (2005) and Fulford et al. (2006).

${ }^{30}$ As Morse (2007, p. 220) seems to suggest: "If one has a taste for deep philosophical problems, free will is of course worth thinking about. The issue is an endlessly interesting evergreen that will never be solved to everyone's satisfaction. But if one thinks about the problem in this sense, one is doing philosophy, not forensic work."

${ }^{31}$ For instance, in one of the most influential philosophical papers on freedom and moral responsibility, Freedom and Resentment, P.F. Strawson (2003, p. 73) explains a compatibilist position in the following way: “( $(.$.$) what 'freedom' means here is nothing but the$ absence of certain conditions the presence of which would make moral condemnation or punishment inappropriate. They [compatibilists] have in mind conditions like compulsion by another, or innate incapacity, or insanity, or other less extreme forms of psychological disorder (...)." See also Galen Strawson (2003, p. 222): "Compatibilists believe that one can be a free and morally responsible agent even if determinism is true. Roughly, they claim, with many variations of detail, that one may correctly be said to be truly responsible for what one does, when one acts, just so long as one is not caused to act by any of a certain set of constraints (kleptomanic impulses, obsessional neuroses, desires that are experienced as alien, post-hypnotic commands, threats, instances of force majeure, and so on)."
} 
mental disorders relevant to their arguments. Therefore, they too might be interested in cooperative research on moral responsibility and mental disorder. In my view, psychiatrists should invite philosophers to direct their attention to their problems, and try to link philosophical to psychiatric expertise.

In conclusion, there are different views on how to understand and define free will. Some understand free will as doing things for reasons, or as being the source of one's actions, others understand free will in terms of alternative possibilities, or in terms of control. Whatever the exact view on free will, there is a widespread intuition - among, e.g., forensic psychiatrists and philosophers-that it is first of all free will that is required for moral responsibility. Given the psychiatrists task, it would be strange and artificial when psychiatrists would have to assess responsibility or accountability while avoiding thinking about free will. Still, not all issues related to free will are relevant to forensic work; the compatibility question can and should be distinguished from the ethical issue of what is required for moral responsibility. The conceptual challenges connected to this ethical issue are directly related to the forensic task and they should encourage rather than deter psychiatrists to think about them within the context of interdisciplinary (psychiatrists, philosophers and lawyers) research. In this way the clarity — and therefore quality—of forensic assessments could be improved.

Acknowledgements This work is financially supported by NWOVENI research-Grant no. 275-20-016.

Open Access This article is distributed under the terms of the Creative Commons Attribution Noncommercial License which permits any noncommercial use, distribution, and reproduction in any medium, provided the original author(s) and source are credited.

\section{References}

Benson, P. 1987. Freedom and value. The Journal of Philosophy 84(9): 465-486.

Bok, H. 1998. Freedom and responsibility. Princeton: Princeton University Press.

Bolton, D. 2008. What is mental disorder? An essay in philosophy, science, and values. Oxford: Oxford University Press.

Buchanan, A. 2008. Commentary: Freedom and function. The Journal of the American Academy of Psychiatry and the Law 36: 25-26.

Eastman, N. 1992. Psychiatric, psychological, and legal models of man. International Journal of Law and Psychiatry 15: 157-169.

Elliot, C. 1996. The rules of insanity. Moral responsibility and the mentally ill offender. Albany: State University of New York Press.

Felthous, A.R. 2008. The will: From metaphysical freedom to normative functionalism. The Journal of the American Academy of Psychiatry and the Law 36: 16-24.

Fischer, J.M. 1994. The metaphysics of free will. An essay on control. Malden: Blackwell.
Fischer, J.M., and M. Ravizza. 1998. Responsibility and control. A theory of moral responsibility. Cambridge: Cambridge University Press.

Frankfurt, H.G. 2003. Some thoughts concerning PAP. In Moral responsibility and alternative possibilities. Essays on the importance of alternative possibilities, ed. McKenna and Widerker, 339-345. Burlington: Ashgate.

Fulford, K.W.M., T. Thornton, and G. Graham. 2006. Oxford textbook of philosophy and psychiatry. Oxford: Oxford University Press.

Ginet, C. 2003. In defense of the principle of alternative possibilities: Why I don't find Frankfurt's argument convincing. In Moral responsibility and alternative possibilities. Essays on the importance of alternative possibilities, ed. McKenna and Widerker, 75-90. Burlington: Ashgate.

Green, C.M., L.J. Naismith, and R.D. Menzies. 1991. Criminal responsibility and mental disorder in Britain and North America: A comparative study. Medicine, Science and the Law 31(1): 4554.

Hoff, P. 1998. Emil Kraepelin and forensic psychiatry. International Journal of Law and Psychiatry 21(4): 343-353.

Kane, R. 1998. The significance of free will. Oxford: Oxford University Press.

Kane, R. 1999. Responsibility, luck, and chance: reflections on free will and indeterminism. The Journal of Philosophy 96: 217-240.

Kane, R. (ed.). 2002. The Oxford handbook of free will. Oxford: Oxford University Press.

Kawohl, W., and E. Habermeyer. 2007. Free will: Reconciling German civil law with Libet's neurophysiological studies on the readiness potential. Behavioral Sciences and the Law 25: 309320.

Luthe, R., and M. Rösler. 2004. Freedom of will, freedom of action and psychiatry: Concerning the relationship of empirical to intelligible character and so-called freedom of choice in the view of forensic psychiatry. In Philosophy and psychiatry, ed. T. Schramme and J. Thome, 295-308. Berlin: De Gruyter.

Mele, A.R. 2004. Action: Volitional disorder and addiction. In The philosophy of psychiatry. A companion, ed. J. Radden. Oxford: Oxford University Press.

Morse, S.J. 1999. Craziness and criminal responsibility. Behavioral Sciences and the Law 17: 147-164.

Morse, S.J. 2007. The non-problem of free will in forensic psychiatry and psychology. Behavioral Sciences \& the Law 25: 203-220.

Nagel, T. 2003. Freedom. In Free will, ed. G. Watson, 229-256. Oxford: Oxford University Press.

Reich, W. 2000. Psychiatric diagnosis as an ethical problem. In Psychiatric ethics, ed. S. Bloch, P. Chodoff, and S. Green 3rd Ed. Oxford: Oxford University Press.

Sadler, J.D. 2005. Values and psychiatric diagnosis. Oxford: Oxford University Press.

Searle, J.R. 2007. Freedom \& neurobiology. Reflections on free will, language, and political power. New York: Columbia University Press.

Sebanz, N., and W. Prinz (eds.). 2006. Disorders of volition. Cambridge: MIT Press.

Stanford Encyclopedia of Philosophy-Compatibilism. http:// plato.stanford.edu/entries/compatibilism (by M. McKenna).

Stanford Encyclopedia of Philosophy-Free Will. http:// plato.stanford.edu/entries/freewill (by T. O'Connor).

Stanford Encyclopedia of Philosophy-Moral Responsibility. http:// plato.stanford.edu/entries/moral-responsibility (by A. Eshleman).

Strawson, G. 2003. The impossibility of moral responsibility. In Free will, ed. G. Watson, 212-228. Oxford: Oxford University Press.

Strawson, P.F. 2003. Freedom and resentment. In Free will, ed. G. Watson, 72-93. Oxford: Oxford University Press. 
Van Inwagen, P. 1986. Ability and responsibility. In Moral responsibility, ed. J.M. Fischer, 153-173. Ithaca: Cornell University Press.

Van Marle, H. 2000. Forensic psychiatric services in the Netherlands. International Journal of Law and Psychiatry 23(5-6): 515-531.

Wallace, R.J. 1994. Responsibility and the moral sentiments. Cambridge: Harvard Univeristy Press.

Wallace, R.J. 2002. Précis of Responsibility and the moral sentiments. Philosophy and Phenomenological Research 64(3): 680-681.
Walter, H. 2001. Neurophilosophy of free will. From libertarian illusions to a concept of natural autonomy. Massachusetts: MIT Press.

Watson, G. (ed.). 2003. Free will. Oxford readings in philosophy. Oxford: Oxford University Press.

Wilson, S., and G. Adshead. 2004. Criminal responsibility. In The philosophy of psychiatry. A companion, ed. J. Radden, 296-311. Oxford: Oxford University Press. 